\title{
Triagem neonatal para hemoglobinopatias no Rio de Janeiro, Brasil
}

\author{
Clarisse Lopes de Castro Lobo, ${ }^{1}$ Leíse Marcelo Bueno, ${ }^{2}$ Patricia Moura, ${ }^{1}$ \\ Leila Loureiro Ogeda, ${ }^{2}$ Shirley Castilho ${ }^{3}$ e Silvia Maia Farias de Carvalho ${ }^{2}$
}

RESUMO Objetivo. Descrever os principais resultados do programa de triagem neonatal para a doença falciforme do Estado do Rio de Janeiro em 15 meses de funcionamento (agosto de 2000 a novembro de 2001).

Métodos. A partir de agosto de 2000, amostras de sangue passaram a ser coletadas de todos os recém-nascidos atendidos em postos de atenção básica à saúde no Estado para triagem neonatal da doença falciforme. Essas amostras são submetidas a cromatografia líquida de alta resolução. Se o cromatograma resultante for compatível com a doença falciforme, a criança e seus pais são encaminhados para confirmação diagnóstica e tratamento.

Resultados. De agosto de 2000 a novembro de 2001, 99260 recém nascidos participaram da triagem. Houve um caso de homozigose para $\mathrm{Hb} \mathrm{C}$. Um em cada 27 recém-nascidos triados pelo programa apresentou o traço falciforme ( $\mathrm{Hb} \mathrm{AS}$ ). A doença falciforme foi constatada em 83 casos (um caso novo para cada 1196 nascimentos): 62 Hb S, 18 Hb SC, 3 Hb SD. Uma criança não compareceu para confirmação diagnóstica. As 82 crianças acompanhadas apresentaram 15 intercorrências (infecções de vias aéreas superiores, febre, seqüestro esplênico, síndrome mãopé e crises de vaso-oclusão), motivando sete internações. Houve necessidade de transfusão sangüinea em 15 crianças, mas nenhuma tornou-se alo-imunizada. Os demais bebês estão evoluindo satisfatoriamente com o uso de penicilina profilática.

Conclusões. Nossos dados evidenciam a importância do diagnóstico precoce da doença falciforme, de forma a prevenir e evitar as freqüentes complicações infecciosas enfrentadas por esses pacientes.

Palavras-chave Globinas, genética, anemia hemolítica congênita.

As hemoglobinopatias compreendem um grupo de distúrbios hereditários que afetam os genes responsáveis pela síntese globinas. Esses distúrbios

\footnotetext{
1 Instituto Estadual de Hematologia Arthur de Siqueira Cavalcanti (HEMORIO), Serviço de Hematologia Clínica, Rio de Janeiro, Brasil. Correspondência e pedidos de separatas devem ser enviados a esta autora no seguinte endereço: Instituto Estadual de Hematologia Arthur Siqueira Cavalcanti - HEMORIO, Rua Frei Caneca 08, Centro, CEP 20211-030, Rio de Janeiro, RJ, Brasil. Fone: +55-21-2509-1290; fax: +55-21-2224-7030; e-mail: dt@hemorio.rj.gov.br

2 HEMORIO, Serviço de Laboratórios.

3 HEMORIO, Serviço de Hemoterapia.
}

são expressos como uma alteração qualitativa ou quantitativa da síntese das globinas, com menor sobrevida das hemácias e conseqüente anemia crônica. A incidência das hemoglobinopatias é de aproximadamente 4,5\% na população mundial. Devido à alta incidência, essas desordens passaram a representar um grave problema de saúde pública em muitos países (1).

Dentre as hemoglobinopatias, a doença falciforme (homozigose SS, dupla heterozigose SC, S beta talassemia e SD) é a patologia hereditária monogênica mais freqüente e a mais impac- tante, por sua alta prevalência e pela gravidade de suas manifestações clínicas. A doença atinge aproximadamente $2 \%$ da população da África equatorial. Antes da instalação de programas de triagem neonatal, apenas $2 \%$ das crianças doentes atingiam 5 anos de idade, sendo a infecção bacteriana a maior causa de complicações nesses pacientes, seguida por febre, seqüestro esplênico e síndrome mão-pé. Esses programas apontam para prevalência média de $2 \%$ da população triada (2). A doença é causada por uma mutação no gene da globina beta, que 
origina uma hemoglobina $(\mathrm{Hb})$ anormal, denominada hemoglobina " $\mathrm{S}$ " ( $\mathrm{Hb} \mathrm{S})$. A Hb S substitui a hemoglobina normal, denominada hemoglobina "A" (Hb A) (3).

Em indivíduos portadores do traço falciforme ( $\mathrm{Hb} \mathrm{AS})$, existe produção tanto de $\mathrm{Hb} \mathrm{A}$ quanto de $\mathrm{Hb} \mathrm{S}$, o que resulta em um fenótipo normal (4). Os pais de indivíduos afetados (com doença falciforme ativa) são portadores assintomáticos de um único gene mutado (heterozigotos AS), transmitindo, cada um deles, o gene alterado para a criança, que assim recebe dois genes anormais (homozigoto SS) $(5,6)$. Segundo estimativas da Organização Mundial da Saúde (OMS), a cada ano nascem cerca de 300000 crianças afetadas por hemoglobinopatias (7).

A doença falciforme se originou na África e foi trazida à América pela imigração forçada dos escravos (8). No Brasil, distribui-se heterogeneamente, sendo mais freqüente onde a proporção de antepassados negros da população é maior (Região Nordeste e estados de São Paulo, Rio de Janeiro e Minas Gerais). Nessas regiões, observase o surgimento de um novo caso de doença falciforme para cada 1000 nascimentos e a presença de um portador do traço em cada 27 nascimentos. Estima-se que, a cada ano, nascem cerca de 2500 crianças com a doença falciforme no Brasil $(9,10)$.

As manifestações clínicas da doença falciforme são resultantes de dois processos característicos: anemia severa e vaso-oclusão. A anemia resulta da meia-vida mais curta das células eritróides contendo primariamente $\mathrm{Hb} \mathrm{S}$; enquanto as hemácias normais circulam por aproximadamente 120 dias, as que contêm $\mathrm{Hb} \mathrm{S}$ circulam por apenas 10 a 20 dias, levando os pacientes a apresentarem anemia de moderada a severa. O segundo, e fisiopatologicamente mais complexo, resultado da homozigose para $\mathrm{Hb} \mathrm{S}$ é a vasooclusão. O efeito intravascular causado pela mudança espacial da $\mathrm{Hb}$ leva à formação de feixes helicoidais que alteram sobremaneira a permeabilidade da membrana a íons, a relação hemácia/vaso e a agregação hemácia/hemácia e hemácia/vaso (11). As diversas formas de doença falciforme se caracterizam por anemia crônica e fenômenos de vaso-oclusão de intensidade variável, que levam a episódios de dores ósteo-articulares que podem ser incapacitantes, exigindo internações hospitalares freqüentes. $\mathrm{Na}$ infância, as infecções e crises de vasooclusão intra-esplênica (seqüestro esplênico) são as principais causas de mortalidade, podendo atingir $20 \%$ das crianças afetadas antes dos 5 anos de idade (11-13). As crianças que ultrapassam essa barreira inicial enfrentam os efeitos da vaso-oclusão crônica. Ao longo dos anos, são essas pequenas tromboses o fator determinante para o desgaste dos órgãos, que leva aos infartos pulmonares, hepáticos e cerebrais, insuficiência renal e retardo do crescimento e da maturação sexual, com comprometimento progressivo de múltiplos órgãos. Tais fenômenos alteram expressivamente a qualidade de vida do indivíduo, com redução da capacidade de trabalho e da expectativa de vida $(6,11-14)$.

Embora a hidroxiuréia tenha se tornado uma valiosa forma de tratamento para reduzir a freqüência de vasooclusão, as transfusões continuam entre as formas mais freqüentemente utilizadas de tratamento das complicações agudas e crônicas da doença falciforme (15). É importante diferenciar indicações para transfusão aguda e condições que requerem terapia transfusional crônica. Sob algumas circunstâncias, uma simples transfusão é requerida por baixa de hematócrito, enquanto em outras é importante substituir células com $\mathrm{Hb}$ SS por hemácias normais, através da transfusão de troca (16). Isso leva a uma alta freqüência de alo-imunização em pacientes com a doença falciforme, devido à estimulação antigênica induzida pelas transfusões repetidas. A freqüência dessa complicação varia de 0 a 35\%, conforme descrito na literatura (17).

Tais eventos correspondem à história natural da doença; entretanto, a experiência de centros médicos internacionais tem mostrado uma redução importante da mortalidade pela doença falciforme. Nesses centros, após o diagnóstico neonatal, é disponibilizada assistência médica, incluindo medidas preventivas de vacinação e uso da penicilina profilática. Dentre as medidas preventivas, destacam-se as orientações dadas aos familiares no tocante ao reconhecimento precoce das complicações mais freqüentes. Tais medidas reduzem a taxa de mortalidade para menos de $5 \%$ nos primeiros 5 anos de vida. Conforme descrito, a sobrevida média passou de 20 anos na década de 1970 para 45 anos no homem e 55 anos na mulher na década de $1990(13,18)$.

Em agosto de 1997, a Secretaria de Saúde do Estado do Rio de Janeiro, Brasil, iniciou a implantação do Programa de Prevenção e Controle das Doenças Congênitas Endocrinometabólicas e Hemoglobinopatias do Estado, através da triagem neonatal (Programa Primeiros Passos). Em agosto de 2000 foi iniciada a triagem neonatal para hemoglobinopatias no Rio de Janeiro, através do Instituto Estadual de Hematologia Arthur de Siqueira Cavalcanti (HEMORIO). O objetivo do presente trabalho foi descrever os principais resultados da triagem neonatal para a doença falciforme no Estado do Rio de Janeiro em 15 meses de funcionamento do programa (agosto de 2000 a novembro de 2001).

\section{MATERIAIS E MÉTODOS}

O programa de triagem para hemoglobinopatias no HEMORIO é desenvolvido por uma equipe multidisciplinar e envolve desde a realização do exame até o atendimento e acompanhamento do doente. Para a realização do teste para triagem de hemoglobinas, o sangue é coletado em papel de filtro através de punção no calcanhar da criança no posto de atenção básica à saúde e então encaminhado ao HEMORIO, onde as amostras são cadastradas no sistema de informática, sendo posteriormente enviadas ao laboratório.

A metodologia adotada para análise das amostras é a cromatografia líquida de alta resolução (HPLC) realizada no equipamento Variant II (Bio-Rad). Nesse equipamento, o programa sickle 
cell é utilizado para detecção e identificação de $\mathrm{Hb}$ F, A, S, D, C e E em recémnatos, utilizando HPLC associada à cromatografia de troca catiônica. As amostras são diluídas em água reagente e mantidas a $12{ }^{\circ} \mathrm{C}$ em câmara de amostra automática. Cada amostra é seqüencialmente injetada no sistema de fluxo de análise, uma amostra a cada 3 minutos, o que favorece uma rápida análise. Um fotômetro de filtro com comprimento de onda duplo (415 e $690 \mathrm{~nm}$ ) monitora a eluição de hemoglobina da coluna, detectando as alterações de absorbância a $415 \mathrm{~nm}$. O filtro secundário de $690 \mathrm{~nm}$ corrige a linha de base para efeitos provocados pela mistura dos tampões com forças iônicas diferentes. As mudanças das absorbâncias são monitoradas e exibidas na forma de cromatograma da absorbância versus tempo.

Cada $\mathrm{Hb}$ apresenta um tempo de retenção característico. Ao final da análise de cada amostra, uma cópia do cromatograma com dados do relatório é automaticamente impresso (figura 1). Nos casos de resultados compatíveis com a doença falciforme, a assistente social do programa entra imediatamente em contato com o posto de coleta para a busca ativa dessa criança, já agendando uma primeira consulta.

Por ocasião dessa consulta, no HEMORIO, é feita a confirmação diagnóstica e a abertura do prontuário. A mãe é submetida aos seguintes exames: eletroforese de $\mathrm{Hb}$ e sorologia para hepatite A, B e C; vírus da imunodeficiência humana (HIV); vírus T-linfotrópico humano (HTLV); citomegalovírus (CMV); sífilis; e toxoplasmose. O pai é submetido a eletroforese de $\mathrm{Hb}$; e a criança é submetida a eletroforese de $\mathrm{Hb}$, hemograma, reticulócitos e estudo imuno-hematológico. $\mathrm{O}$ estudo imuno-hematológico inclui pesquisa de anticorpos irregulares e fenotipagem eritrocitária para os principais antígenos dos sistemas de grupos sangüíneos Rh, Kell, Kiddy, Duffy, MNS e Lewis.

Nessa primeira consulta são fornecidas aos pais noções básicas de puericultura. Orienta-se a palpação do baço e a identificação dos sinais de alerta do agravamento da doença. Também
FIGURA 1. Cromatogramas de hemoglobinas por técnica de cromatografia líquida de alta resolução, Instituto Estadual de Hematologia Arthur de Siqueira Cavalcanti (HEMORIO), Estado do Rio de Janeiro, Brasila
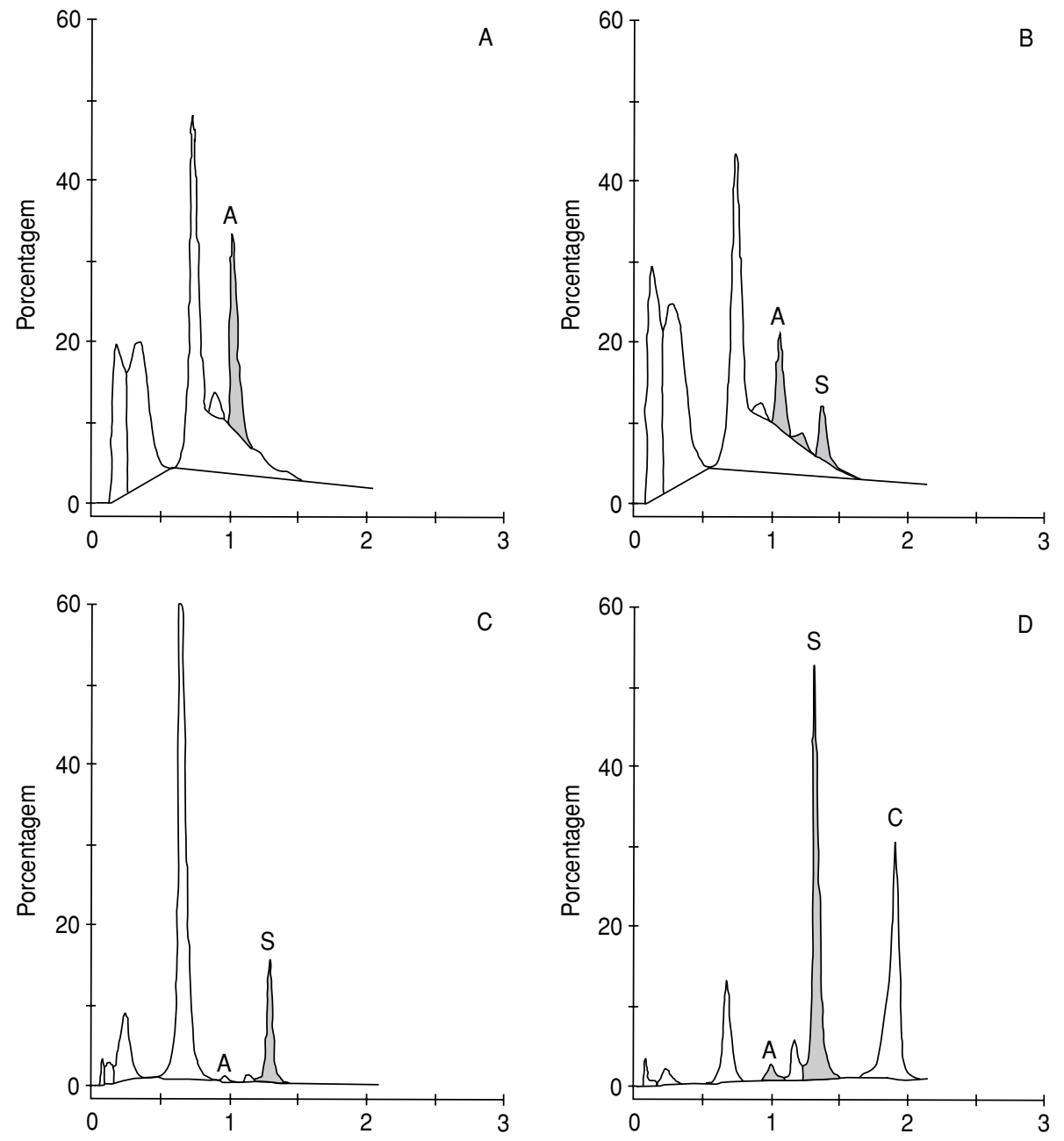

A) $\mathrm{Hb} \mathrm{A}$; B) $\mathrm{Hb} \mathrm{AS}$; C) $\mathrm{Hb} \mathrm{S}$; D) Hb SC.

nesse momento é iniciado o tratamento com penicilina oral profilática e ácido fólico. Todo o tratamento é custeado pelo Estado.

\section{RESULTADOS}

No período de agosto de 2000 a novembro de 2001 foram estudadas 99260 amostras de recém-natos pela técnica de HPLC como parte do programa de triagem neonatal para hemoglobinopatias. Como mostra a tabela 1, a análise dessas amostras revelou os seguintes resultados: 94513 crianças

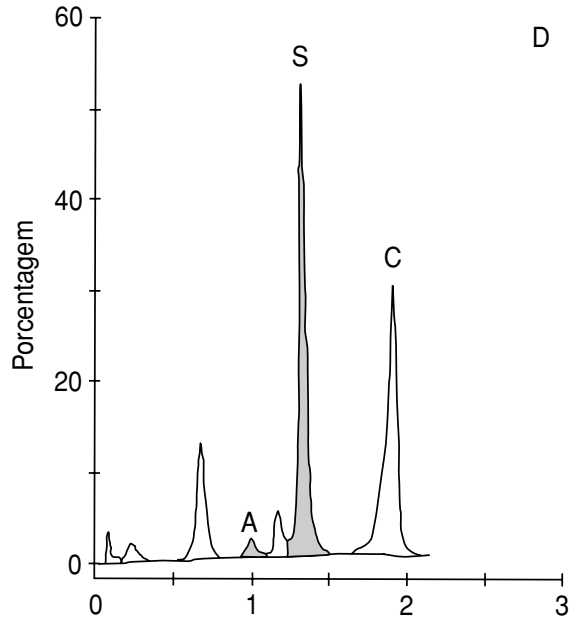

$(95,22 \%)$ apresentaram padrão normal de $\mathrm{Hb} ; 83$ crianças $(0,08 \%)$ apresentaram doença falciforme, o que significa um caso em cada 1196 recémnascidos; em uma criança $(0,01 \%)$ foi detectada homozigose para $\mathrm{Hb} \mathrm{C}$. Em 4663 neonatos $(4,7 \%)$ foi observada a presença do traço falciforme ( $\mathrm{Hb} \mathrm{AS}$ ), o que significa uma criança AS em cada 27 recém-nascidos.

Os resultados normais e de portadores do traço falciforme foram encaminhados aos respectivos postos de coleta. Os portadores do traço foram orientados pela própria equipe do posto de atenção básica à saúde, já treinada 
TABELA 1. Resultados de triagem neonatal para a doença falciforme, Instituto Estadual de Hematologia Arthur de Siqueira Cavalcanti (HEMORIO), Estado do Rio de Janeiro, Brasil, agosto de 2000 a novembro de 2001

\begin{tabular}{lrc}
\hline Padrão de hemoglobinas & No. & $\%$ \\
\hline Normal (Hb A) & 94513 & 95,22 \\
Doença falciforme & 62 & 0,06 \\
Hb S & 18 & 0,02 \\
Hb SC & 3 & 0,01 \\
Hb SD & 1 & 0,01 \\
Outras hemoglobinopatias & & \\
$\quad$ Hb C & 3933 & 3,96 \\
Traço falciforme & 588 & 0,59 \\
Hb AS & 142 & 0,14 \\
Hb AC & 99260 & 100 \\
Hb AD & & \\
$\quad$ Total & &
\end{tabular}

pelo HEMORIO. As crianças com o traço falciforme recebem o resultado do exame no posto de coleta acompanhado de manual explicativo e da carteira que identifica sua condição de portador.

Todas as 83 crianças identificadas como afetadas foram rastreadas pela equipe de assistência básica e encaminhadas ao HEMORIO. Dessas, apenas uma não compareceu. $\mathrm{O}$ conselho tutelar do município foi notificado do caso, porém a criança persiste sem acompanhamento no HEMORIO.

Oitenta e duas crianças apresentaram 15 intercorrências (infecções de vias aéreas superiores, febre, seqüestro esplênico, síndrome mão-pé e crises de vaso-oclusão), motivando sete internações em cinco bebês. Houve necessidade de transfusão sangüínea em 15 crianças, mas nenhuma tornou-se aloimunizada. As demais crianças estão evoluindo satisfatoriamente com o uso de penicilina profilática.

\section{DISCUSSÃO}

O programa de triagem neonatal para hemoglobinopatias do Estado do Rio de Janeiro precedeu em 10 meses a portaria do Ministério da Saúde, de junho de 2000, que preconiza a realização da triagem em todo o território brasileiro. Conforme demonstrado em nosso trabalho, a cada 1196 crianças nascidas no Estado do Rio de Janeiro, uma é portadora de doença falciforme, e uma em cada 27 possui o traço falciforme. O diagnóstico da doença ao nascimento permite alguns tipos de intervenção que podem diminuir a morbidade e a mortalidade nessas crianças, com destaque para a orientação aos familiares sobre o que é a doença, reconhecimento precoce das eventuais complicações, acompanhamento médico sistemático, uso profilático de antibióticos a partir da confirmação da doença, para prevenção das infecções bacterianas, e implementação de esquema adicional de imunização.

As infecções bacterianas severas são a principal causa de morbidade e mortalidade nos pacientes com doença falciforme. Observa-se nesses indivíduos uma maior susceptibilidade às infecções por germes encapsulados, notadamente Streptococcus pneumoniae e Haemophilus influenzae. A septicemia e a meningite por Streptococcus pneumoniae são a causa mais comum de morte na infância nos pacientes com doença falciforme (18-20). Nos nossos casos, as infecções foram as intercorrências que mais exigiram intervenção, motivando $50 \%$ das internações ocorridas nos pacientes diagnosticados pelo programa de triagem neonatal.

Também é interessante observar que, por ocasião da implantação do programa, encontravam-se em acompanhamento no HEMORIO 1659 pa- cientes com doença falciforme, entre crianças e adultos de ambos os sexos. Nesses pacientes, o diagnóstico só foi feito após o aparecimento dos primeiros sintomas da doença, tendo sido observada a ocorrência, neste mesmo período de observação, de 83 óbitos, o que representa uma taxa de mortalidade de 5,06\%. O grupo incluía 464 crianças entre 0 e 12 anos que apresentaram uma taxa de mortalidade de $16,5 \%$, sendo que 44 óbitos ocorreram até os 4 anos de idade. Além disso, $6,3 \%$ encontravam-se na faixa de 45 a 60 anos, e apenas $1,5 \%$ tinham mais de 60 anos. A síndrome torácica aguda, as infecções e as crises de vaso-oclusão intra-esplênica, que levam a um grande número de transfusões, foram as principais causas de mortalidade identificadas, mostrando claramente que os pacientes morrem de intercorrências agudas (21).

Por outro lado, com a implantação do programa de triagem neonatal para hemoglobinopatias, apenas cinco dos 82 bebês em acompanhamento tiveram necessidade de internação, dois por seqüestro esplênico e três por quadro infeccioso. Apesar da necessidade de transfusão sangüínea em 15 das 82 crianças acompanhadas, devido ao protocolo de fenotipagem adotado pelo HEMORIO nenhuma tornou-se alo-imunizada. As demais estão evoluindo bem com o uso de penicilina profilática.

Alguns trabalhos têm evidenciado que o risco de septicemia e meningite é cerca de $10 \%$ em crianças com $\mathrm{Hb}$ SS, com aproximadamente dois terços dos casos ocorrendo antes dos 2 anos de idade $(19,20)$. Tal dado é confirmado em nossa casuística, pois entre os pacientes com doença falciforme acompanhados antes da implantação do programa de triagem neonatal, $12 \%$ dos óbitos ocorreram por septicemia (21). Vale ressaltar a ausência de septicemia e meningite entre os bebês com doença falciforme identificados e acompanhados precocemente, em que pese o pequeno período de implantação do programa (iniciado em agosto de 2000).

Nos Estados Unidos, dados de um centro com larga experiência em tria- 
gem neonatal mostraram que 3,6\% de todos os neonatos de raça negra eram portadores de hemoglobinopatias e que a doença falciforme ocorreu em um entre cada 951 nascimentos (13). No Brasil, devido à grande miscigenação da população, torna-se impossível definir a origem genética do indivíduo através da cor de pele. Portanto, é possível afirmar que os dados apresentados, de um caso novo em 1196 nascimentos, correspondem à prevalência da doença falciforme no Estado do Rio de Janeiro. O mesmo trabalho norte-americano comparou ainda a sobrevida entre os pacientes diagnosticados após 3 meses de idade e acompanhados por cerca de 9,4 anos, cuja taxa de mortalidade foi de $8 \%$, e os pacientes diagnosticados no período neonatal, cuja taxa de mortalidade foi de apenas $1,8 \%$ (13).

Conforme mencionado anteriormente, entre os pacientes acompanhados no HEMORIO antes da implantação do programa de triagem neonatal, cujo diagnóstico foi feito após o aparecimento dos primeiros sintomas, a taxa de mortalidade global foi de $5,06 \%$, e a taxa de mortalidade até 12 foi de 16,5\%. Entre os pacientes diagnosticados através da triagem neo- natal, a taxa de mortalidade após 18 meses de implantação do programa é igual a zero. Esses dados indicam que a triagem neonatal para hemoglobinopatias é o primeiro passo para reduzir a morbidade e mortalidade nos indivíduos com doença falciforme. Contudo, o sucesso da triagem depende também do acompanhamento complementar simultâneo feito por programas de aconselhamento genético, além da garantia de acompanhamento médico aos pacientes com doença falciforme; esse modelo representa um inegável avanço na garantia do direito à saúde para essa população.

\section{REFERÊNCIAS}

1. Steinberg MH, Hebbel RP. Clinical diversity of sickle cell anemia: genetic cellular modulation of disease severity. Am J Hematol 1983; 14(4):404-416.

2. Stine OC, Dover GJ, Zhu D, Smith KD. The evolution of two West African populations. J Mol Biol 1992;34(4):336-344.

3. Antonarakis SE, Boehm CD, Searjeant GG, Theisen CE, Dover GJ, Kazazian HH. Origin of beta-S globin gene in blacks: the contribution of recurrent mutation or gene conversion or both. Proc Natl Acad Sci USA 1984;81(3): 853-856.

4. Sears DA. The morbidity of sickle cell trait. A review of the literature. Am J Med 1978;64(6): 1021-1036.

5. Bookcchin RM, Lew VL. Pathophysiology of sickle cell anemia. Hematol Oncol Clin North Am 1996;10(6):1241-1253.

6. Chien S, Usami S, Bertles JF. Abnormal rheology of oxygenated blood in sickle cell anemia. J Clin Invest 1970;49:623-634.

7. World Health Organization (WHO). Update on the progress of haemoglobinopathies control. Report of the 3rd and 4th Annual Meetings of the WHO Working Group for the Community Control of Hereditary Anemias. Bangkok: WHO; 1985.

8. Frempong KO. Sickle cell disease in the United States of America and Africa. Hematology (Am Soc Hematol Educ Program) 1999:64-71.
Disponível em http://www.hematology.org/education/hematology99.cfm. Acessado em 31 de janeiro de 2003.

9. Zago MA, Costa FF, Bottura C, Ione IG. Hereditary hemoglobin disorders in a Brazilian population. Human Hered 1983;33(2):125- 129.

10. Zago MA, Costa FF, Freitas TC, Bottura C. Clinical, hematological and genetic features of sickle cell anemia and sickle beta-thalassemia in a Brazilian population. Clin Gen 1980;18(1): 58-64.

11. Ballas SK, Mohandas N. Pathophysiology of vaso-occlusion. Hematol Oncol Clin North Am 1996;10(6):1221-1239.

12. Ballas SK. Sickle cell disease current clinical management. Sem Hematol 2001;38(4):307313.

13. Vichinsky E, Hurst D, Earles A, Kleman K, Lubin B. Newborn screening for sickle cell disease: effect on mortality. Pediatrics 1988; 81(6):749-755.

14. Eckman JR. Sickle cell anemia and the management of the adult patient with frequent pain. Hematology (Am Soc Hematol Educ Program) 1999:51-57. Disponível em http://www. hematology.org/education/hematology99. $\mathrm{cfm}$. Acessado em 31 de janeiro de 2003.

15. Searjeant GR. Chronic transfusion programmes in sickle cell disease: problem or panacea? Br J Haematol 1997;97(2):253-255.
16. Telen MJ. Principles and problems of transfusion in sickle disease. Semin Hematol 2001; 38(4):315-323.

17. Cox JV, Steane E, Cunningham G, Frenkel EP. Risk of alloimmunization and delayed hemolytic transfusion reactions in patients with sickle cell disease. Arch Intern Med 1988, 148(11):2485-2489.

18. Platt OS, Brambilla DJ, Rosse WF, Milner PF, Castro O, Steinberg MH, et al. Mortality in sickle cell disease: life expectancy and risk factors for early death. N Engl J Med 1994; 330(23):1639-1644.

19. Powars D, Overturf G, Weiss J, Lee S, Chan L. Pneumococcal septicemia in children with sickle cell anemia: changing trend of survival. JAMA 1981;245(18):1839.

20. Lobel JS, Bove KE. Clinicopathologic characteristics of septicemia in sickle cell disease. Am J Dis Child 1982;136(6):543-547.

21. Lobo CLC, Cerqueira ER, Leite ACC. Study of the risk factors associated to mortality in sickle cell disease (SCD). Blood 2000; 96(11): 19b.

Manuscrito recebido em 26 de março de 2002. Aceito em 2 janeiro de 2003. 
ABSTRACT Objective. To describe the main results obtained in the first 15 months of neonatal screening for sickle cell disease in the state of Rio de Janeiro, Brazil, from August 2000 to November 2001.

Neonatal screening Methods. Starting in August 2000, blood samples began to be collected for sickle cell for hemoglobinopathies disease screening from all newborns receiving care in primary health care clinics in the state of Rio de Janeiro. The samples were submitted to high-resolution liquid chromatography. If the resulting chromatogram was compatible with sickle cell disease, the child and the parents were referred for diagnostic confirmation and treatment.

Results. Between August 2000 and November 2001, 99260 newborns were screened. There was one case of homozygous $\mathrm{Hb}$ C. On average, one of every 27 newborns who were screened presented sickle cell trait ( $\mathrm{Hb} \mathrm{AS})$. Sickle cell disease was observed in 83 cases, or one new case in each 1196 births. The 83 consisted of: $62 \mathrm{Hb} \mathrm{S}, 18 \mathrm{Hb} \mathrm{SC}$, and $3 \mathrm{Hb} \mathrm{SD}$. One child did not appear for diagnostic confirmation. The 82 children who were followed up by the program presented 15 intercurrent illnesses (upper respiratory infections, fever, splenic sequestration crises, hand-foot syndrome, and vascular occlusion), resulting in seven hospital admissions. Blood transfusions were necessary with 15 children, but none developed alloimmunization. All the other babies were doing well with the use of prophylactic penicillin.

Conclusions. Our data show the importance of early diagnosis for sickle cell disease, so as to prevent the frequent infectious complications faced by these patients.

\title{
Epidemiology Courses during Summer Session School of Public Health, The University of Michigan
}

\author{
Dates: $\quad$ 6-25 July 2003 \\ Location: School of Public Health, The University of Michigan \\ Ann Arbor, Michigan, United States of America
}

The 2003 Graduate Summer Session in Epidemiology of the University of Michigan School of Public Health will offer 3 three-week courses, 35 one-week courses, and 2 weekend courses. The three-week courses are: Fundamentals of Biostatistics, Fundamentals of Epidemiology, and Epidemiology in Public Health Practice. The one-week courses cover such topics as infectious diseases, injuries, computer applications in epidemiology, diseases of aging, clinical trials, genetics in epidemiology, occupational and environmental epidemiology, women's health, violence, bioterrorism, and successful scientific writing. The weekend courses will deal with genetics in epidemiology and geographic information systems for epidemiology.

The cost for a three-week course taken on a non-credit basis is US\$ 700; taking the same course for graduate credit costs US\$ 2 093. For a one-week course, the respective fees are US\$ 400 and US\$ 801 . Students must also pay for their own housing costs and meals. The deadline to apply for the summer session is 1 June 2003.

\author{
Information: \\ Jody Gray \\ Graduate Summer Session in Epidemiology \\ Department of Epidemiology, School of Public Health \\ The University of Michigan \\ 109 Observatory Street \\ Ann Arbor, MI 48109-2029, United States of America \\ Telephone: (734) 764-5454 • Fax: (734) 764-3192 \\ E-mail: umichgss@sph.umich.edu \\ Internet: http://www.sph.umich.edu/epid/GSS
}

